\title{
Discriminación salarial indirecta y los sistemas de valoración de puestos de trabajo*
}

\section{Indirect wage discrimination and job valuation systems}

\author{
MirentXu Marín MaLo* \\ Profesora Ayudante Doctora de Derecho del Trabajo \\ y de la Seguridad Social \\ Universidad Pública de Navarra \\ ORCID ID: 0000-0002-9081-6155
}

Recibido: $15 / 2 / 2021$

Aceptado: $26 / 3 / 2021$

doi: https://doi.org/10.20318/femeris.2021.6135

\begin{abstract}
Resumen. La realidad demuestra que la desigual valoración de puestos de trabajo es una de las causas que explican la brecha salarial de género. Hasta ahora se ha realizado un considerable esfuerzo por la normativa y jurisprudencia con el fin de identificar las situaciones de discriminación salarial, sin embargo, resulta necesario dar un paso más y apostar por la incorporación de sistemas de valoración de puestos de trabajo neutros. En el presente artículo se analizan los diversos sistemas de valoración de puestos existentes y su virtualidad para garantizar una valoración neutra en cuanto al género. En su análisis se tiene en cuenta las aportaciones que la jurisprudencia ha realizado para identificar los factores que pueden estar en el origen de una valoración discriminatoria cuanto al género.

Palabras clave: sistema de valoración de puesto de trabajo; discriminación indirecta; desigualdad salarial; brecha salarial, mujer.
\end{abstract}

Abstract. Reality shows that the unequal valuation of jobs is one of the causes that explain the gender pay gap. Until now, a considerable effort has been made by regulations and jurisprudence, to identify situations of wage discrimination, however, it is necessary to go one step further and bet on the incorporation of neutral job evaluation systems. This article analyzes the different job evaluation systems and their potential to guarantee a gender-neutral evaluation. Its analysis considers the contributions that jurisprudence has made to identify the factors that are at the origin of an assessment can discriminate in terms of gender.

Keywords: job evaluation systems; indirect discrimination; gender pay; wage gap; woman.

\section{Introducción}

En las últimas décadas, los gobiernos y organismos internacionales han buscado promover la igualdad entre hombres y mujeres en diferentes ámbitos, especialmente, en el ámbito laboral. Con este objetivo se ha promulgado numerosa normativa dirigida a ase-

\footnotetext{
*Este artículo fue merecedor, a juicio de la Comisión de Igualdad de la Asociación Española de Derecho del Trabajo y la Seguridad Social, del Premio 8M convocado por la Asociación Española de Derecho del Trabajo y la Seguridad Social.

${ }^{* *}$ mirentxu.marin@unavarra.es
} 
gurar la no diferenciación en derechos y deberes laborales basada en el género. Desde un punto de vista teórico, la normativa ha ido incorporando medidas dirigidas al respeto de este derecho. Así, el derecho a la igualdad entre hombres y mujeres es un principio del ordenamiento jurídico de la Unión Europea desde su propia fundación. Asimismo, es uno de los valores fundamentales de nuestra Constitución, recogido en su art. 14 como la prohibición de discriminación por razón de sexo, que impregna el resto de normativa nacional.

Sin embargo, y pese a ser un derecho asumido y reconocido por la gran mayoría de la población, la realidad es que se está lejos de conseguir una igualdad efectiva entre hombres y mujeres. La desigualdad entre hombres y mujeres es una realidad desde el momento mismo del acceso al empleo que continúa a lo largo de la carrera profesional y afecta, por ejemplo, a la promoción de la mujer en la empresa, a sus prestaciones en materia de seguridad social y, de manera especialmente significativa, al salario percibido por el trabajo realizado.

Los últimos datos publicados señalan que, en la Unión Europea, las mujeres ganan de media casi un 15\% menos que los hombres ${ }^{1}$. En España, esta diferencia salarial se sitúa en un $13,9 \%{ }^{2}$. Además, un informe realizado por la Comisión Europea indica que esta brecha salarial no ha cambiado durante la última década ${ }^{3}$. Es posible afirmar, por lo tanto, que la brecha salarial es una realidad. Sin embargo, debe tenerse en cuenta que la llamada brecha salarial puede llevar aparejada una desigualdad salarial -es decir, un pago diferente por el mismo trabajo o trabajo de igual valor- o tener su origen en otros factores, como la feminización de los trabajos a tiempo parcial o el conocido como "techo de cristal" que impide a las mujeres, de manera indirecta, la promoción en la empresa. En cualquier caso, los datos señalan que parte de esa brecha salarial, aunque no toda, está causada por la desigualdad salarial entre hombres y mujeres ${ }^{4}$.

Dentro de las causas que dan lugar a la discriminación salarial está la incorrecta valoración del trabajo realizado por mujeres y hombres, sin utilizar una escala uniforme o dando más valor a aquellos aspectos del trabajo masculinos frente a otros que podrían considerarse femeninos.

El presente texto pretende analizar la utilidad de los sistemas de valoración de puestos de trabajo en la lucha contra la desigualdad salarial por razón de sexo. Así, se pretende determinar cómo las nuevas herramientas para la valoración de puestos de trabajo son un instrumento esencial en la lucha contra la desigualdad salarial entre hombres y mujeres reconocido por el art. 28 del Real Decreto Legislativo 2/2015, de 23 de octubre, por el que se aprueba el texto refundido de la Ley del Estatuto de los Trabajadores (en adelante, TRET) y, por tanto, un elemento imprescindible para las empresas que quieran respetar

\footnotetext{
${ }^{1}$ Datos publicados por el Parlamento Europeo en el año 2020. Disponibles en: https://www.europarl.europa.eu/ news/es/headlines/society/20200227ST073519/brecha-salarial-de-genero-en-europa-hechos-y-cifras-infografia

2 Debe tenerse en cuenta, en todo caso, que los datos de la Unión Europea son cuatrienales (encuestas realizadas durante un periodo de cuatro años).

${ }^{3}$ BOLL, C. y LAGERMAN, A.: Gender pay gap in EU countries based on SES, Comisión Europea, Fondazione Giacomo Brodolini, Roma, 2018, pp. 4 y 17 entre otras.

${ }^{4}$ En este sentido, véase BALLESTER PASTOR, M.A.: "La discriminación retributiva por razón de sexo en la Unión Europea”, en Documentación Laboral, no 115, 2018, Vol. III, Cinca, Madrid, 2018, p. 14.
} 
el principio de igualdad retributiva entre hombres y mujeres, entendiendo este como el cobro de la misma retribución por la realización de un trabajo igual o de igual valor.

En la lucha para lograr la igualdad retributiva entre hombres y mujeres son numerosas las herramientas disponibles, tal como puede comprobarse de una rápida visita al sitio web del Instituto de la Mujer5. Sin embargo, las dos herramientas a las que este organismo otorga mayor valor son a la Herramienta de Autodiagnóstico de Brecha Salarial de Género $^{6}$ y al Sistema de Valoración de Puestos de Trabajo con Enfoque de Género ${ }^{7}$.

Como ya se ha señalado, el presente texto se centrará en la segunda de ellas: los sistemas de valoración de puestos de trabajo como medio para luchar contra la discriminación salarial por razón de sexo. En este sentido, debe señalarse que, tal como se verá posteriormente, si bien la mayoría de estos sistemas son, en apariencia, objetivos, puede producirse discriminación indirecta en su aplicación práctica. Por ello, el objetivo del presente artículo es determinar en qué ocasiones y de qué manera estos sistemas pueden generar desigualdad retributiva, con el fin de establecer la forma de evitarla.

Para lograr el objetivo planteado se estudiarán, en primer lugar, los conceptos de desigualdad salarial, discriminación indirecta y valoración de puestos de trabajo, con el objetivo de delimitar el espacio de cada uno en la lucha contra la desigualdad salarial y de analizar la interrelación entre ellos. Al hilo de este análisis, se profundizará en la importancia de garantizar un sistema de valoración de puestos de trabajo neutro y en cómo el legislador español ha tratado de introducir tímidamente esta obligación. A continuación, se analizará la jurisprudencia existente en la materia con el fin de determinar en qué situaciones y respecto a qué criterios se ha considerado la existencia de discriminación salarial en las empresas. Para ello, se revisarán los factores que deben ser tenidos en cuenta en el uso de los diferentes sistemas de valoración de puestos de trabajo a la luz de la jurisprudencia existente, con el fin de determinar cuáles de ellos pueden incurrir en discriminación salarial indirecta por no resultar del todo neutros. Se analizarán, además, los principales tipos de sistemas de valoración de puestos de trabajo y las características que diferencian unos de otros. Además, se tratarán de ofrecer soluciones para evitar este problema a la hora de aplicar la herramienta en la empresa.

\section{De la prohibición de discriminación salarial indirecta a la valoración neutra de puestos de trabajo}

Como se ha señalado en la introducción, el derecho a la igualdad retributiva entre hombres y mujeres es uno de los principios básicos tanto en el ordenamiento jurídico de la Unión Europea como en el nacional. Sin embargo, no siempre ha sido así. La prohibición

\footnotetext{
${ }^{5}$ https://www.inmujer.gob.es/servRecursos/portada/home.htm

${ }^{6}$ Esta herramienta permite a las empresas realizar un análisis detallado sobre su sistema retributivo que determinará la existencia o no de diferencias salariales vinculadas al género.

${ }^{7}$ Ambas herramientas son de acceso gratuito y están disponibles en: https://www.inmujer.gob.es/areasTematicas/ IgualdadEmpresas/IgualdadSalarial.htm
} 
de discriminación salarial indirecta se ha introducido paulatinamente en la normativa internacional e interna. Además, a la concreción de este concepto ha contribuido de forma decisiva la jurisprudencia europea y constitucional.

Resulta, por ello, necesario comenzar este estudio analizando la evolución normativa y jurisprudencial en el tratamiento a la discriminación salarial indirecta, con el objetivo de determinar el importante papel que, en la actualidad, pueden jugar los sistemas de valoración de puestos de trabajo a la hora de alcanzar la igualdad retributiva en las empresas, dando así cumplimiento al contenido del art. 28 TRET.

1. Evolución del concepto de discriminación salarial indirecta en la normativa y jurisprudencia

En las últimas décadas, se ha producido un esfuerzo legislativo y social dirigido a acabar con la discriminación por razón de sexo que en algunas ocasiones tenía su origen en la propia regulación normativa. Desde 1951 la promoción de la igualdad salarial ha sido un objetivo de la Organización Internacional del Trabajo (en adelante, OIT), que ya en su Convenio 100 abordaba esta cuestión.

En el ámbito comunitario, el Tratado de Funcionamiento de la Unión Europea (en adelante, TFUE) establece como objetivo de la Unión, en su art. 8, la eliminación de "las desigualdades entre el hombre y la mujer". En el mismo sentido, la Directiva 76/207/CEE del Consejo, de 9 de febrero de 1976, relativa a la aplicación del principio de igualdad de trato entre hombres y mujeres en lo que se refiere al acceso al empleo (en adelante, Directiva 76/207/CEE), señala, en su art. 2.1, que este principio de igualdad supone "la ausencia de toda discriminación por razón de sexo, bien sea directa o indirectamente". Esta prohibición general de no discriminación también se encuentra en el art. 14 de la Constitución Española (en adelante, CE).

Con relación a la igualdad retributiva entre hombres y mujeres, la Declaración Universal de Derechos Humanos ${ }^{8}$ establece, en su art. 23.2 que "toda persona tiene derecho, sin discriminación alguna, a igual salario por trabajo igual". Este derecho también se recoge en otros tratados internacionales, como el Pacto Internacional de derechos económicos, sociales y culturales de $1966^{9}$ así como en diferentes documentos de la Convención sobre eliminación de todas las formas de discriminación contra la mujer (en adelante, CEDAW $)^{10}$. También la OIT lleva años impulsando la igualdad retributiva, tal como hemos señalado, a través de Convenios como el núm. 100 sobre igualdad de remuneración entre la mano de obra masculina y la mano de obra femenina por un trabajo de igual valor.

Por su parte, el TFUE establece la obligación de los Estados miembros de garantizar la igualdad salarial; en concreto, mediante "la aplicación del principio de igualdad de retribución entre trabajadores y trabajadoras para un mismo trabajo o para un trabajo de igual

\footnotetext{
${ }^{8}$ Adoptada por la Asamblea General de la Organización de Naciones Unidas el 10 de diciembre de 1948.

${ }^{9}$ En su art. 7.i establece el principio de igualdad retributiva por trabajos de igual valor.

${ }^{10}$ Entre ellos, la Recomendación General número 13 de la CEDAW sobre igualdad de remuneración por trabajo de igual valor.
} 
valor"11. Este principio también aparece recogido en nuestro ordenamiento jurídico interno. Así, el art. 28 TRET establece que "el empresario está obligado a pagar por la prestación de un trabajo de igual valor la misma retribución ... sin que pueda producirse discriminación alguna por razón de sexo en ninguno de los elementos o condiciones de aquella". El Tribunal Constitucional ha señalado que, en todo caso, "el principio de no discriminación en materia salarial entraña el mantenimiento de una concepción de estricta igualdad salarial, no solo cuando existe identidad de trabajo sino -en consonancia con las reglas interpretativas sobre esta materia emanadas de la jurisprudencia del TJCE y asumidas, vía art. 10.2 CE por este Tribunal-cuando se detecta la existencia de trabajos de igual valor"12.

Tal como ha señalado la Comisión Europea, "la igualdad de género es uno de los valores fundamentales de la Unión Europea. Sin embargo, no es una realidad en el trabajo"13. La existencia de la brecha salarial en el sistema laboral es innegable, pues año tras año los datos confirman esta realidad ${ }^{14}$. El Instituto Nacional de Estadística señala, en su informe sobre el salario anual y la brecha salarial de género, que la brecha salarial fue, en el año 2018, de 6,5 puntos en la jornada a tiempo completo y de 20,6 en la jornada a tiempo parcial $^{15}$. Por su parte, un informe europeo mostró, en el año 2016, como la brecha salarial entre hombres y mujeres aumenta a medida que las mujeres entran en el mercado laboral, mostrando que estas últimas ganan, de media, un 16\% menos que los hombres, manteniéndose esta diferencia salarial a lo largo de los últimos años ${ }^{16}$. Eurostat ha definido esta brecha como "la diferencia entre el salario bruto por hora de los hombres y el de las mujeres expresado como porcentaje del salario bruto por hora de los hombres".

Pese a los avances normativos, e incluso a la aceptación social del principio de "a igual trabajo, igual salario"17, la brecha salarial sigue siendo una realidad fruto, en parte, de la discriminación indirecta ${ }^{18}$. La discriminación indirecta no solo existe, sino que en el medio laboral se ha convertido en un problema que, si bien no surge de la redacción de los preceptos

${ }^{11}$ Art. 157.1 TFUE.

${ }^{12}$ STC (Sala Primera) núm. 286/1994, de 27 de octubre (rec. 175/1994), FJ Tercero.

${ }^{13}$ Comunicación de la Comisión al Parlamento Europeo, al Consejo y al Comité Económico y Social Europeo. Plan de Acción de la UE 2017-2019. Abordar la brecha salarial entre hombres y mujeres, 2017, p. 1. Documento disponible en: https://eur-lex.europa.eu/legal-content/ES/TXT/?uri=CELEX\%3A52017DC0678

${ }^{14}$ En este sentido, véase GOÑI SEIN, J.L.: "La reducción de la brecha salarial de género a través de la transparencia y el registro salarial”, en RODRÍGUEZ SANZ DE GALDEANO, B. (Dir.); et. al.: La discriminación de la mujer en el trabajo y las nuevas medidas legales para garantizar la igualdad de trato en el empleo, Aranzadi, Cizur Menor, 2020, pp. 81 y ss.

${ }^{15}$ Información disponible en: https://www.ine.es/ss/Satellite?c=INESeccion_C\&param3=1259924822888\&p=125 4+35110672\&pagename=ProductosYServicios\%2FPYSLayout\&cid $=1259925408327 \& \mathrm{~L}=0$

${ }^{16}$ BOLL, C.; LEPPIN, J.; ROSSEN, A. y WOLF, A.: Magnitude and impact factors of the gender pay gap in EU Countries, Dirección General de Justicia y Consumidores de la Comisión Europea, 2016. Documento disponible en: https://www. hwwi.org/fileadmin/hwwi/Publikationen/Publikationen_PDFs_2016/Magnitude_And_Impact_Factors_All.pdf

${ }^{17}$ Interpretando salario en el sentido más amplio de retribución, tal como ha señalado el TJCE en su sentencia de 17 de mayo de 1990 (C-262/88), apartado 12.

${ }^{18}$ En este sentido, el Código práctico sobre la aplicación de la igualdad de retribuciones entre mujeres y hombres para un trabajo de igual valor, EMAKUNDE, Bilbao, 1997, señala en su p. 6 que "a pesar de las disposiciones... las diferencias de retribución entre las mujeres y los hombres siguen siendo considerables", y añade que los datos muestran "una divergencia importante entre los salarios de las mujeres y los de los hombres en todos los Estados miembros". En el mismo sentido, una investigación realizada en la Universidad Complutense de Madrid señala que "ciertos indicadores siguen confirmando, hoy, la existencia en nuestro entorno europeo y en España de la brecha salarial", en CASAS BAAMONDE, M.E.; MENÉNDEZ CALVO, R.; QUINTANILLA NAVARRO, B. y SERRANO GARCÍA, J.M.: Herramientas para combatir la brecha salarial. Análisis de los factores que influyen en la brecha salarial, Comisión Ejecutiva Confederal UGT, Madrid, 2015, p.13. 
legales $^{19}$, aparece en la aplicación práctica de la norma. De esta manera, la brecha salarial surge de la falta de neutralidad de los sistemas retributivos y en la toma en consideración de factores con un impacto desigual en mujeres y hombres ${ }^{20}$, lo que genera diferencias salariales injustificadas y, por tanto, discriminatorias. Tal como señala BALLESTER PASTOR, "la situación del trabajo de la mujer parte de la existencia de dos realidades separadas: la jurídica y la social, que transcurren en paralelo sin necesariamente coincidir"21.

Al igual que el concepto de discriminación por razón de sexo o el de igualdad retributiva forman parte de nuestro ordenamiento jurídico desde hace décadas, ocurre lo mismo con el concepto de discriminación indirecta. Como ya se ha señalado, la prohibición de discriminación de cualquier tipo viene recogida en el art. 2 de la Directiva 76/207/CEE. Más adelante, la Directiva 97/80/CE, de 15 de diciembre de 1997, sobre inversión en la carga de la prueba en los casos de discriminación por razón de sexo (en adelante, Directiva 97/80/ CE) señaló que existirá discriminación indirecta "cuando una disposición, criterio o práctica aparentemente neutra afecte a una proporción sustancialmente mayor de miembros de un mismo sexo salvo que dicha disposición, criterio o práctica, no resulte adecuada y necesaria o pueda justificarse con criterios objetivos que no estén relacionados con el sexo" 22 . Se trata, pues, de una discriminación que tiene como origen a la propia sociedad y su funcionamiento, sin estar vinculada, al menos de manera directa, al sexo ${ }^{23}$. Tal como señala BALLESTER PASTOR, "la ausencia de un motivo malévolo no convierte una medida aparentemente discriminatoria en neutra o viceversa" ${ }^{24}$, por lo que todo aquello que genera una diferencia de trato entre hombres y mujeres, aunque la causa no esté relacionada directamente con el sexo, debe ser analizado para eliminar los factores que promueven dicha diferenciación.

Las diferencias salariales entre hombres y mujeres son causa, en numerosas ocasiones, de una mala categorización profesional en la empresa. Esto genera que existan "puestos con diferentes funciones que tienen asignada la misma categoría (por ejemplo, los celadores con tareas puramente administrativas y los celadores con tareas sanitarias) y puestos con las mismas funciones que tienen asignadas diferentes categorías (por ejemplo, los celadores con tareas administrativas y los auxiliares administrativos) ${ }^{25}$. A este problema se añade la masculinización o feminización de ciertos puestos de trabajo. Esto supone que ciertos puestos de trabajos, como el de celadores, ha estado tradicionalmente ocupado por hombres, frente a puestos con similares funciones, como el de auxiliar de enfermería, ocupado principalmente por mujeres.

\footnotetext{
${ }^{19}$ En este sentido, véase TORRENTE GARI, S.: La mujer y la protección social, Ministerio de Trabajo y Asuntos Sociales; Madrid; 1999; p. 17.

${ }^{20}$ En este sentido, véase CASAS BAAMONDE, M.E.; MENÉNDEZ CALVO, et. al.: Herramientas para combatir..., op. cit.

${ }^{21}$ BALLESTER PASTOR, M.A.: "Normativa nacional en materia de igualdad de trato en el ámbito laboral de la Seguridad Social”, en Revista Doctrinal Aranzadi, 1998, p. 1.

${ }^{22}$ Art. 2 Directiva 97/80/CEE.

${ }^{23}$ En este sentido, véase FERNÁNDEZ DOMínGUEZ, J.J.: La mujer ante el Derecho de la Seguridad Social. Antiguos y nuevos problemas de la igualdad de trato por razón de sexo, La Ley, Madrid, 1999, p. 11.

${ }^{24}$ BALLESTER PASTOR, M.A.: Diferencia y discriminación normativa por razón de sexo en el orden laboral, Tirant Lo Blanch, Valencia, 1994, pp. 163 y ss.

${ }^{25}$ COVES, A.M.; LUSA, A.; MARTÍNEZ, C. y ORTEGA, M.A.: "Aplicación de la valoración de puestos de trabajo como herramienta para combatir la discriminación salarial", en I Workshop de ingeniería de Organización, Bilbao, 2000 , p. 277. Valoración de puestos de trabajo con perspectiva de género, Instituto de la Mujer, Madrid, 2015, p.12.
} 
Es en este punto donde los sistemas de valoración de puestos de trabajo cobran una especial importancia. Se entiende por "valoración de puestos de trabajo" al proceso llevado a cabo en una empresa con el objetivo de determinar el valor que tiene cada puesto de trabajo dentro de la empresa. Es decir, con esta herramienta se pretende "distinguir, cualitativa y cuantitativamente, entre los empleos que conforman la organización" 26. Para ello, es necesario obtener toda la información posible con relación a las características y exigencias de las tareas desempeñadas en cada puesto de trabajo de la empresa ${ }^{27}$.

De este modo, la valoración de puestos de trabajo pretende ser un método objetivo que permita establecer el valor de los diferentes puestos de trabajo sin que el resultado pueda verse afectado por cuestiones de género. Para ello, se analiza cada factor del puesto de manera independiente, pero bajo un mismo criterio de puntuación que se presupone objetivo. De esta forma, a mayor valor, mayor salario y viceversa.

Debe tenerse en cuenta que el puesto de trabajo, así como su valor, no solo determina las funciones que debe realizar la persona trabajadora, sino también el salario que esta va a percibir de acuerdo con el convenio colectivo de aplicación ${ }^{28}$. De la misma manera, los sistemas de valoración de puestos son utilizados como herramienta para "determinar la retribución o un componente de la retribución para cada puesto de trabajo" 29. Por todo lo anterior, la implantación de este tipo de herramientas en las empresas cobra una especial importancia en la lucha contra la discriminación salarial indirecta y contra la brecha salarial que, como se ha señalado anteriormente, sigue siendo, hoy en día, un problema importante no solo en nuestro país, sino en toda la Unión Europea. Lo que este tipo de herramienta puede aportar en la lucha contra la discriminación salarial por razón de sexo es la posibilidad de analizar el contenido de cada puesto de trabajo desde una perspectiva neutra, y otorgando un salario en función del valor del trabajo realizado. Ello supondría, entre otras cosas, que la feminización de una categoría profesional concreta no seguiría generando desigualdad, pues en el análisis no importa el perfil de quienes ocupan el puesto sino el contenido del trabajo desarrollado en este.

Sin embargo, para que esto sea posible, resulta necesario realizar un análisis de aquellos factores tenidos en cuenta en el proceso de valoración de puestos de trabajo que pueden llegar a generar una discriminación salarial indirecta la empresa.

2. La valoración de puestos de trabajo como condición necesaria en la lucha contra la discriminación salarial indirecta

Tal como señalan algunos autores, los sistemas de valoración de puestos de trabajo son, en sí mismos, "una forma de combatir la discriminación salarial de la mujer, ya que

\footnotetext{
${ }^{26}$ PEREDA MARÍN, S. y BERROCAL BERROCAL, F.: Valoración de puestos de trabajo, Eudema, Madrid, 1993, p. 9.

${ }^{27}$ En este sentido, véase FERNÁNDEZ RIOS, M.: Análisis y descripción de puestos de trabajo, Ediciones Díaz de Santos, Madrid, 1995, p. 55.

${ }^{28}$ PEREDA MARÍN, S. y BERROCAL BERROCAL, F.: Valoración de puestos..., op. cit., p. 9

${ }^{29}$ COROMINAS, A.; COVES, A.M.; LUSA, A.; MARTÍNEZ, M.C. y ORTEGA, M.A.: “El papel de la valoración de puestos de trabajo en la discriminación salarial de la mujer", Encuentro Mujer y Trabajo. Un debate sobre la igualdad, Santander, 1999, p.4.
} 
como su nombre indica, se valora el puesto de trabajo en función de los requerimientos de la tarea desempeñada y de la naturaleza de la misma, independientemente de la persona que lo ocupa en un momento dado" ${ }^{30}$. En todo caso, tal como ha señalado el Instituto de la $\mathrm{Mu}-$ jer, esta herramienta permite también "visibilizar y afrontar el hecho de que aún mujeres y hombres no ganan lo mismo por la realización del mismo trabajo o de trabajos distintos, pero de igual valor" 31 .

El art. 28 TRET establece que las personas trabajadoras deben recibir un mismo salario por un trabajo de igual valor, y obliga al empresario a asegurar dicha igualdad retributiva. Además, la modificación de este artículo aprobada en el Real Decreto-ley 6/2019, de 1 de marzo, de medidas urgentes para garantía de la igualdad de trato y de oportunidades entre mujeres y hombres en el empleo y la ocupación incluyó una definición sobre qué se entendería sobre "trabajo de igual valor". En concreto, la actual redacción del art. 28 TRET señala que se entenderá que dos trabajos son de igual valor cuando se determine equivalencia entre "las funciones o tareas efectivamente encomendadas, las condiciones educativas, profesionales o de formación exigidas para su ejercicio, los factores estrictamente relacionados con su desempeño y las condiciones laborales". De lo dispuesto en este artículo cabe concluir que, para evitar la discriminación salarial por razón de sexo debe analizarse el contenido específico de cada puesto de trabajo de forma objetiva. Esa necesidad de analizar en detalle diferentes características de los puestos de trabajo convierte a los sistemas de valoración de puestos de trabajo en una herramienta imprescindible para hacer efectivo el principio de igual salario por igual trabajo.

A este respecto, y tal como señalan algunos autores, "existe un amplio consenso acerca de que los procedimientos de asignación de puntos por factor son los más adecuados, tanto en lo que respecta genéricamente a la valoración de puestos de trabajo como desde el punto de vista de la discriminación salarial de la mujer" 32.

Por todo lo anterior, estos sistemas son esenciales para luchar contra la discriminación salarial por razón del género, pero deben ser aplicados de manera correcta, objetivados y con criterios que resulten neutrales en su aplicación.

Sin embargo, la aplicación de sistemas de valoración de puestos de trabajo como elemento determinante para la fijación del salario, si bien resulta ser, en apariencia, un método objetivo, no elimina completamente la subjetividad y además, puede resultar objetivo sin ser neutro en cuanto al respeto a la igualdad entre hombres y mujeres ${ }^{33}$. Por ello resulta imprescindible implementar la perspectiva de género en estos sistemas, con el fin de lograr la neutralidad de estos.

A este respecto, el Instituto de la Mujer ha señalado que "para que la aplicación de estos sistemas sirva para combatir la desigualdad, es necesario que la evaluación se lleve a cabo libre de sesgos de género" ${ }^{34}$. Es decir, deben seleccionarse factores con criterios neu-

\footnotetext{
${ }^{30}$ COVES, A.M.; LUSA, A.; et. al.: “Aplicación de la valoración de puestos...”, op. cit., p. 278.

${ }^{31}$ Valoración de puestos de trabajo con perspectiva de género..., op. cit., p.3.

${ }^{32}$ COROMINAS, A.; COVES, A.M.; et. al.: “El papel de la valoración de puestos de trabajo...”, op. cit., p. 5. Igualmente, COVES, A.M.; LUSA, A.; et. al.: “Aplicación de la valoración de puestos...”, op. cit., p. 278.

${ }^{33}$ En este sentido, véase COROMINAS, A.; COVES, A.M.; et. al.: “El papel de la valoración de puestos...” op. cit., p.4.

${ }^{34}$ Valoración de puestos de trabajo con perspectiva de género..., op. cit., p.12.
} 
tros y sin olvidar la segmentación por sexos de los puestos de trabajo, con el fin de evitar que algunos factores y su valoración puedan favorecer a hombres o mujeres.

Para evitar caer en una falta de neutralidad, deben tenerse en cuenta algunas buenas prácticas a la hora de determinar los factores a analizar y su puntuación; es decir, a la hora de establecer el funcionamiento del sistema de valoración de puestos de trabajo. La primera de ellas y más importante es que se debe garantizar que el sistema de valoración de puestos de trabajo "se aplique a todos y cada uno de los puestos de trabajo existentes en la organización, ya que lo que se pretende es determinar el valor relativo de los puestos" 35 y, de no hacerlo así, se estaría obteniendo información sesgada que podría incurrir en discriminación indirecta por razón de género.

Para lograr la neutralidad, el sistema deberá estar descrito de forma completa y detallada. Los factores deberán estar definidos con claridad, teniendo en cuenta para ello el contenido del art. 28 TRET con relación a lo que debe tenerse en cuenta en la consideración de varios trabajos como de igual valor. Será necesario, además, marcar claramente las diferencias de puntuación en cada caso. Además, el método debe asegurar que la valoración de un mismo puesto de trabajo por dos personas distintas llevará a un resultado similar. Para ello, es importante definir claramente los procedimientos para la descripción de los puestos de trabajo, su evaluación y su clasificación y justificar la puntuación otorgada en cada caso. Las cualidades que se evalúan en cada factor también deben quedar claras y, en todo caso, deberá ser accesible a todo el personal para que pueda ser consultado en cualquier momento ${ }^{36}$.

Además, organismos como el Instituto de la Mujer o la OIT recomiendan que estos sistemas sean consensuados entre empresa y personal, y que el grupo de trabajo esté formado en equidad sexual y representado por personas trabajadoras de las diferentes categorías profesionales de la empresa ${ }^{37}$. La OIT ha señalado que una buena conformación del grupo de trabajo para determinar el proceso y contenido de la valoración de puestos de trabajo tendrá ventajas, pues asegurará la coherencia del proceso y permitirá conocer de forma completa el problema de la igualdad salarial y la evaluación de los empleos en la empresa $^{38}$. En cuanto a la presencia de mujeres en los mismos, afirma que ello contribuirá a "detectar mejor los requisitos descuidados de los empleos femeninos", lo cual, tal como se verá en el próximo apartado, es una de las principales causas que acaban generando discriminación salarial indirecta ${ }^{39}$ y que el legislador ha intentado eliminar al señalar, en el art. 28 TRET, que deben tenerse en cuenta factores como la formación o las condiciones en que se desempeña el trabajo. Es decir, teniendo en cuenta factores que resultan aplicables tanto a hombres como a mujeres sin favorecer a ninguno de los dos sexos.

\footnotetext{
${ }^{35}$ COVES, A.M.; LUSA, A.; et. al.: “Aplicación de la valoración de puestos de trabajo...”, op. cit., p. 279.

${ }^{36}$ Valoración de puestos de trabajo con perspectiva de género..., op. cit., p.12. En similar sentido, COROMINAS, A.; COVES, A.M.; et. al.: “El papel de la valoración de puestos..., op. cit., pp. 10 y ss.

${ }^{37}$ En este sentido, véase Guía y recomendaciones de uso de la herramienta sistema de valoración de puestos de trabajo en las empresas con perspectiva de género, Instituto de la Mujer. Igualmente, Promoción de la igualdad salarial por medio de la evaluación no sexista de los empleos: Guía detallada, OIT, Ginebra, 2008, p. 8. Documento disponible en: https:// www.ilo.org/wcmsp5/groups/public/---ed_norm/---declaration/documents/publication/wcms_101326.pdf

${ }^{38}$ Promoción de la igualdad salarial..., op. cit., p. 9.

${ }^{39}$ Ibidem..., p. 10.
} 
Para determinar qué factores deben ser tenidos en cuenta, de manera especial, a la hora de diseñar el sistema de valoración de puestos de trabajo asegurando su neutralidad, se analizará, a continuación, a la luz de la jurisprudencia existente en la materia, cuáles de estos factores -que, como se verá posteriormente, forman parte del contenido básico que se analizará en la valoración de puestos de trabajo- generan o pueden generar discriminación indirecta en su aplicación práctica ${ }^{40}$.

\section{Factores detrminantes en el diseño del sistema de valoración de puestos de tra- bajo en aras de la neutralidad}

Pese a defender que los sistemas de valoración de puestos de trabajo cuantitativos son los más adecuados, en tanto que se ajustan a lo establecido en el art. 28 TRET para determinar cuándo dos trabajos son "de igual valor"41 y resultan ser objetivos, no puede obviarse que "la selección de factores, la definición de los niveles de cada factor, la descripción de los puestos y la ponderación de los factores son, al menos en parte, subjetivas y están condicionadas socialmente" ${ }^{\prime 2}$.

Son numerosas las sentencias que han abordado la problemática de la discriminación salarial indirecta por razón de sexo, tanto a nivel europeo cono nacional. En general, en estas sentencias se pone de manifiesto cómo la discriminación salarial indirecta está causada, en muchas ocasiones, por una deficiente valoración de los puestos de trabajo que lleva a entender que dos puestos no realizan un trabajo de igual valor cuando sí lo hacen.

Como se ha señalado anteriormente, el TJCE realizó una interpretación del art. 119 del Tratado Constitutivo de la Comunidad Económica Europea (en adelante, TCCEE) y de la Directiva 75/117/CEE en lo referido a la aplicación del principio de igualdad retributiva. En concreto, señaló que existirá desigualdad salarial cuando, ante un "mismo trabajo" o "trabajo de igual valor" dos trabajadores de diferente sexo percibiesen una retribución distinta sin una causa objetiva y suficiente que lo justificase ${ }^{43}$. En similar sentido, la STC (Sala Primera) núm. 286/1994, de 27 de octubre (rec. 175/1994) puso de manifiesto, en su Fundamento Jurídico Tercero, que para probar la inexistencia de discriminación retributiva entre categorías o departamentos segregados sexualmente y con niveles retributivos diferentes, "el criterio de comprobación no puede ser la identidad formal de las tareas, sino la igualdad del valor del trabajo". Dicho de otro modo, no basta con que se realicen tareas distintas para justificar la diferencia salarial, sino que debe analizarse el valor del

\footnotetext{
${ }^{40}$ En este sentido, véase COVES, A.M.; LUSA, A.; et. al.: “Aplicación de la valoración de puestos...”, op. cit., p. 278, donde señalan los autores que "el propio sistema de valoración puede tener aspectos discriminatorios, en su definición y en su aplicación en diferentes fases del proceso".

${ }^{41}$ Como se verá posteriormente, este tipo de sistema de valoración de puestos de trabajo analiza factores como las aptitudes necesarias para el puesto analizado, el esfuerzo requerido, el nivel de responsabilidad del trabajador que ocupa el puesto o las condiciones en que se desarrolla el trabajo. Ello está en clara sintonía con lo que el art. 28 TRET señala como factores que determinarían si dos o más trabajos son "de igual valor".

${ }^{42}$ P COROMINAS, A.; COVES, A.M.; et. al.: “El papel de la valoración de puestos...”, op. cit., p. 5.

${ }^{43}$ STJCE de 26 de junio de 2001 (C-381/99), apartado 25 y 30, entre otros.
} 
trabajo con objeto de no atribuir mayor valor al trabajo realizado predominantemente por hombres frente al de mujeres ${ }^{44}$.

Esta misma sentencia señala que se debe entender que existen razones objetivas cuando el empresario "pueda explicar válidamente la diferencia de retribución, especialmente a través de circunstancias que no han sido tenidas en cuenta por el convenio colectivo aplicable a los trabajadores interesados", haciendo referencia, además, a que en todo caso dichas causas deberán respetar el principio de proporcionalidad ${ }^{45}$. En todo caso, y tal como consta en su apartado 67, "el motivo invocado por el empresario para explicar la desigualdad debe responder a una efectiva necesidad de la empresa, ser idóneo para alcanzar el objetivo que ésta persigue y ser necesario a tal fin" ${ }^{46}$. Además, tal como señala la sentencia, deberá siempre tenerse en cuenta si el sistema retributivo de la empresa se basa en la productividad, ya que, de ser así, podrá haber una diferencia salarial, siempre y cuando esta sea "consecuencia de los diferentes resultados del trabajo individual" 47 . Sin embargo, si el criterio no está basado en la producción del trabajador individualmente considerado, sino en el tipo de trabajo realizado, no podrá haber diferencias salariales ${ }^{48}$.

La clave está en determinar qué es un "mismo trabajo" o "trabajo de igual valor", y para ello, deben analizarse los diferentes factores laborales determinantes de la retribución que, aunque en apariencia son neutros, derivan, tal como ha venido señalando los tribunales, en discriminación salarial indirecta por razón de sexo. En los siguientes apartados se analizará la jurisprudencia en torno a cada uno de estos factores.

En el presente apartado se tratará de determinar, en primer lugar, qué se entiende por "mismo trabajo" o "trabajo de igual valor. En segundo lugar, se determinará cuáles son esos factores aparentemente neutros que generan discriminación salarial, así como la importancia de estos en los sistemas de valoración de puestos de trabajo, haciendo que estos supongan una herramienta para la lucha contra la discriminación salarial o, por el contrario, una causa más de discriminación indirecta por razón de sexo

Es preciso adelantar que, el presente apartado se limita a repasar aquellos factores que han sido objeto de jurisprudencia por entender que podían generar discriminación salarial indirecta por razón de sexo, no cada uno de los factores que se han señalado anteriormente como incluidos en los diferentes sistemas de valoración de puestos de trabajo.

\section{Una revisión jurisprudencial al concepto de "mismo trabajo" o "trabajo de igual valor"}

Para determinar qué aspectos de los sistemas de valoración de puestos de trabajo pueden generar discriminación salarial indirecta por razón de sexo es necesario analizar,

\footnotetext{
${ }^{44}$ En este sentido, véase STC (Sala Primera) núm. 286/1994, de 27 de octubre (rec. 175/1994), FJ Tercero.

${ }^{45}$ STJCE de 26 de junio de 2001 (C-381/99), apartado 68.

${ }^{46}$ La STJCE de 26 de junio de 2001 (C-381/99) señala esta cuestión haciendo referencia a la doctrina de este mismo Tribunal planteada en su Sentencia de 13 de mayo de 1986 (C-170/84), apartado 36.

${ }^{47}$ STJCE de 26 de junio de 2001 (C-381/99), apartado 73.

${ }^{48}$ La STJCE de 26 de junio de 2001 (C-381/99), apartados 73 y ss.
} 
en primer lugar, el concepto de "trabajo de igual valor" a la luz de la redacción del art. 28 TRET. Este artículo establece que se entenderá que dos trabajos tienen el mismo valor cuando "la naturaleza de las funciones o tareas efectivamente encomendadas, las condiciones educativas, profesionales o de formación exigidas para su ejercicio, los factores estrictamente relacionados con su desempeño y las condiciones laborales en las que dichas actividades se llevan a cabo en realidad sean equivalentes" ${ }^{49}$.

Esta redacción respecto al concepto de "trabajo de igual valor", es fruto de la interpretación de este por parte del Tribunal de justicia de la Unión Europea (en adelante, TJUE), que ha establecido que el valor de un trabajo debe evaluarse mediante criterios objetivos como pueden ser los requisitos educativos, profesionales y de formación, cualificación, esfuerzo y responsabilidad, el trabajo realizado o la naturaleza de las tareas del puesto evaluado ${ }^{50}$. Como se verá a continuación, el señalado criterio ha sido también aplicado por los tribunales españoles ${ }^{51}$.

En concreto, la STJUE de 28 de febrero de 2013 (C-427/11), señaló que, para demostrar la existencia de causa objetiva que justifique la diferencia salarial cuando existe una aparente discriminación salarial indirecta por razón de sexo, la empresa debe probar que las actividades realizadas por el trabajador y la trabajadora no son comparables y no pueden entenderse como "mismo trabajo" o "trabajo de igual valor". Esta es la primera cuestión que suscita problemas a la hora de determinar la existencia de discriminación salarial indirecta: cuáles son los factores determinantes para comprobar si dos personas realizan un "mismo trabajo" o "trabajo de igual valor". En este sentido, la STJUE de 28 de febrero de 2013 (C-427/11) establece en su apartado 27 que "debe comprobarse si, habida cuenta de un conjunto de factores, como la naturaleza del trabajo, las condiciones de formación y las condiciones laborales, puede considerarse que dichos trabajadores se encuentran en una situación comparable" 52 .

A este respecto, el Tribunal Constitucional ha señalado que, para garantizar la no discriminación, "se han de tener en cuenta criterios de evaluación que, por sí mismos, no sean discriminatorios". Añade, además, que para ello "deberá evidenciarse que se ha recurrido a criterios de evaluación neutros, basados en atributos igualmente predicables de ambos sexos" pues, como determina la Sala, la discriminación por razón de sexo también se produce cuando se valoran en mayor medida trabajos con rasgos y características propias, de manera predominante, de uno de los dos $\operatorname{sexos}^{53}$.

A continuación, se comentarán los diferentes factores señalados cuando se trate de analizar una actividad sea, en apariencia, idéntica.

\footnotetext{
${ }^{49}$ Esta segunda parte del señalado artículo fue introducida por el Real Decreto Ley 6/2019, de 1 de marzo, de medidas urgentes para garantía de la igualdad de trato y de oportunidades entre mujeres y hombres en el empleo y la ocupación.

${ }^{50}$ En este sentido véase la STJCE de 26 de junio de 2001 (C-381/99), apartado 5.

${ }^{51}$ Sirva como ejemplo la STC 147/1995 de 16 de octubre (rec. 652/1993), FJ Segundo.

${ }^{52}$ En similar sentido, STJUE de 11 de mayo de 1999 (C-309/97, apartado 17 y STJUE de 26 de junio de 2001 (C381/99) apartado 43).

${ }^{53}$ STC (Sala Primera) núm. 286/1994, de 27 de octubre (rec. 175/1994), FJ Tercero. En similar sentido, STC (Sala Primera) núm. 58/1994, de 28 de febrero (rec. 205/1991).
} 


\subsection{La formación}

Respecto a la formación debe tenerse en cuenta que se hace referencia a la titulación requerida para la realización de las funciones propias del puesto de trabajo. Esto supone que no se consideraría neutra la exigencia de una determinada acreditación o la valoración de una determinada acreditación si no está justificada con relación a las funciones inherentes del puesto de trabajo.

A este respecto, el TJUE ha señalado que si los trabajadores y trabajadoras incluidos en una misma categoría profesional o dentro de un mismo puesto de trabajo no disponen de la misma habilitación o cualificación profesional deberán tenerse en cuenta otros factores "relativos a la naturaleza de las tareas que pueden encomendarse a cada uno de dichos grupos de trabajadores, a los requisitos de formación exigidos para su ejercicio y a las condiciones laborales en las que dichas tareas se efectúan" ${ }^{54}$. Es decir, el simple hecho de que dos personas tengan un nivel formativo diferente no justifica, per se, la diferencia salarial; pues esta debe basarse en el contenido del propio trabajo.

De esta forma, la cualificación solo será causa objetiva que justifique la diferencia salarial cuando la misma sea requisito sine qua non para desempeñar funciones o tareas específicas del puesto de trabajo. Sin embargo, sí será un criterio que permitirá determinar si las personas trabajadoras efectúan el mismo trabajo ${ }^{55}$.

\subsection{El concepto de tareas de la "misma naturaleza"}

La segunda de las cuestiones que debe analizarse es si realizan tareas de la misma naturaleza. A este respecto, el TJUE ha señalado que, aunque de manera habitual los trabajadores y trabajadoras no desempeñen tareas de la misma naturaleza, deberá considerarse que sí lo hacen cuando cualquiera de ellos pueda ser requerido para realizar las tareas del otro en un momento determinado, aunque no sea lo habitual ${ }^{56}$.

Dentro de la naturaleza de las actividades realizadas deben tenerse en cuenta factores que, aunque son neutros en apariencia, también pueden generar discriminación indirecta. Esto puede darse al valorar puestos de trabajo en los que haga falta el uso de la fuerza física frente a otros cuya exigencia principal sea la habilidad manual. Igual problema plantea la comparación entre dos grupos de trabajadores y trabajadoras en los que, por las funciones desempeñadas en el puesto, los periodos de descanso retribuido son diferentes, la libertad en la organización del trabajo cambia o la nocividad es de diversos grados. Recuérdese que solo habrá discriminación salarial por razón de sexo cuando dos grupos de trabajadores y trabajadoras realicen, si no el mismo trabajo, un trabajo al que se atribuya el mismo valor objetivo.

\footnotetext{
${ }^{54}$ STJUE de 28 de febrero de 2013 (C-427/11) apartados 28 y 29.

${ }^{55}$ STJUE de 11 de mayo de 1999 (C-309/97) apartado 19.

${ }^{56}$ STJUE de 28 de febrero de 2013 (C-427/11) apartados 31 y ss.
} 
Además, tal como ha señalado el Tribunal Constitucional, al comparar varios puestos de trabajo no es necesario que el trabajo desempeñado sea exactamente el mismo, sino que basta con que este sea de "igual valor" para entender que deben ser retribuidos de igual modo ${ }^{57}$. En este sentido, el Tribunal ha señalado que no basta con que las funciones realizadas sean diferentes para justificar la diferencia salarial, sino que lo que debe analizarse es el criterio empleado para fijar el valor del trabajo realizado en cada categoría profesional ${ }^{58}$. Los criterios de valoración empleados deben ser neutros, sin dar más valor a una serie de actividades que requieren "cualidades predominantemente predicables de un sexo". Será la neutralidad del sistema de valoración de puestos lo que permita dirimir la existencia o no de discriminación salarial indirecta por esta causa.

Respecto a lo anterior, hay algunas cuestiones relativas a ciertas características del trabajo realizado que deben ser tenidas en cuenta para asegurar la neutralidad de la valoración de este. Entre ellos, cabe destacar la valoración, como característica esencial del trabajo, de la nocturnidad o la penosidad y esfuerzo físico del mismo.

En cuanto al trabajo nocturno, el Tribunal Constitucional ha señalado que no puede justificar una diferencia en la valoración del puesto de trabajo, puesto que es una característica que ya se retribuye de manera específica atendiendo al convenio colectivo de aplicación, tal como establece el art. 36.2 TRET $^{59}$.

Con relación a la penosidad o el esfuerzo físico, podría decirse que parecen categorías neutras, pues ninguna de ambas tiene por qué ser mejor tolerada por hombres que por mujeres. Sin embargo, la jurisprudencia ha señalado en reiteradas ocasiones que cuando no se demuestre que son características vinculadas al puesto, se estará dando más valor de manera injustificada a una cualidad predominantemente masculina. Además, señala el Tribunal que no pueden obviarse otras características del puesto de trabajo que no adolecen de este sesgo de género, como pueden ser la atención requerida, el cuidado, la asiduidad de una determinada tarea o la responsabilidad derivada del puesto de trabajo; características estas que sí son consideradas neutras ${ }^{60}$. Así, no se podrá dar más valor al trabajo realizado en un puesto vinculado a la penosidad y el esfuerzo cuando estos "se haIlen unidos a la fuerza física y a la resistencia muscular", pues en tal caso se puede deducir que "estaremos ante categorías masculinizadas y, por ende, discriminatorias" 61 . En definitiva, este criterio solo podrá ser utilizado de manera restrictiva, cuando sea un elemento esencial en la actividad analizada y siempre combinándolo con criterios de valoración neutros $^{62}$. En este sentido, la STC (Sala Primera) núm. 198/1996 de 3 de diciembre (rec. 1145/1993) señala, en su FJ Cuarto, que "la posesión de un cierto grado de fuerza física es un elemento más, no el único" a la hora de determinar el valor del trabajo realizado.

\footnotetext{
${ }^{57}$ STC núm. 145/1991, de 1 de julio (rec. 175/1989), FJ Cuarto.

${ }^{58}$ STC núm. 147/1995, de 16 de octubre (rec. 652/1993), FJ Tercero.

${ }^{59}$ En este sentido, véase STC núm. 147/1995, de 16 de octubre (rec. 652/1993), FJ Sexto.

${ }^{60}$ Así lo manifiesta la STC núm. 145/1991, de 1 de julio (rec. 175/1989), FJ Quinto. Siguiendo el mismo criterio se manifiesta la STC núm. 147/1995, de 16 de octubre (rec. 652/1993), FJ Sexto.

${ }^{61}$ STC núm. 147/1995, de 16 de octubre (rec. 652/1993), FJ Sexto. En este sentido, véase también STSJ País Vasco (Sala de lo Social), de 11 de mayo de 2004 (rec. 288/2004), FD Tercero

${ }^{62}$ STC (Sala Primera) núm. 58/1994, de 28 de febrero (rec. 205/1991), FJ Sexto.
} 
En este sentido, debe recurrirse siempre a sistemas de asignación de categorías neutros, sin que puedan ser considerados como tales "aquellos factores o cualidades predominantemente poseídos por el género masculino", salvo que pueda demostrarse de manera objetiva que son factores intrínsecos al puesto y a las funciones a desarrollar en el mismo que le otorguen, además, un valor a ese trabajo diferente al resto. Tal como ha señalado el Tribunal Constitucional, "no cabe adoptar como criterio dominante de valoración, a efectos de anudar una superior retribución, el esfuerzo físico", pues se entiende que este se vincula a los hombres y, por tanto, resultaría discriminatorio ${ }^{63}$.

En todo caso, debe tenerse siempre en cuenta que no basta con demostrar la neutralidad en apariencia o respecto a un único puesto de trabajo, sino que debe demostrarse que la valoración de los factores alegados ha sido ponderada junto con otros factores presentes en los puestos de trabajo, lo que daría como resultado un sistema de valoración transparente y neutral en su conjunto ${ }^{64}$. Así lo ha señalado el Tribunal Constitucional al entender que no basta con "limitarse a constatar que las reglas en materia de clasificación profesional establecen funciones distintas", sino si ese reparto de funciones está ocultando una discriminación indirecta por razón de sexo. Lo que debe hacer es "suministrar una justificación objetiva y razonable, suficientemente probada que eliminase la presunción de discriminación por sexo" 65 , lo que podría hacerse con un buen sistema de valoración de puestos de trabajo que asegure la neutralidad en el proceso.

\section{La negociación colectiva como fuente de discriminación salarial indirecta}

Uno de los factores que no son objeto de la valoración del puesto de trabajo pero que está directamente vinculado a este tipo de herramienta es la propia clasificación profesional. Ello ha sido objeto de análisis por la jurisprudencia, con objeto de determinar si, efectivamente, es una causa objetiva suficiente para justificar la diferencia salarial entre hombres y mujeres el mantenimiento de unas buenas relaciones laborales a través del convenio colectivo de aplicación o la propia "tradición" que mantiene una serie de categorías profesionales en el convenio colectivo sin que sean revisadas en posteriores negociaciones. Generalmente, estas categorizaciones suelen feminizar ciertos trabajos y masculinizar otros que, si se realizase un análisis del valor de estos, resultarían ser trabajos de igual valor.

Con relación a ello, la jurisprudencia es clara. La STJUE de 31 de mayo de 1995 (C400/93) señala que "el principio de igualdad de retribución entre trabajadores y trabajadoras es aplicable también cuando la retribución se fija a través de negociaciones colectivas" 66 . Por tanto, que el convenio colectivo haya fijado una determinada retribución para los diferentes puestos de trabajo no es justificación suficiente ni objetiva para una diferencia

\footnotetext{
${ }^{63}$ STC núm. 147/1995, de 16 de octubre (rec. 652/1993), FJ Segundo.

${ }^{64}$ STC núm. 147/1995, de 16 de octubre (rec. 652/1993), FJ Sexto.

${ }^{65}$ STC (Sala Primera) núm. 286/1994, de 27 de octubre (rec. 175/1994) Antecedente Tercero.

${ }^{66}$ Apartado 46.
} 
salarial. También en este sentido se ha manifestado el Tribunal Constitucional, al señalar que "ni la tradición ni el carácter convencional de las diferencias de trato pueden erigirse en argumentos invocables frente a la discriminación" ${ }^{67}$, independientemente de que, en principio, la diferencia retributiva haya sido pactada en negociación colectiva y de manera legítima, pues el Convenio colectivo también está obligado a respetar los derechos fundamentales recogidos en la Carta Magna, entre los que se encuentra la prohibición de no discriminación por razón de $\operatorname{sexo}^{68}$.

Exactamente lo mismo sucede con el mantenimiento de unas buenas relaciones laborales en la empresa. Tal como señala la STJUE de 28 de febrero de 2013 (C-427/11), este interés empresarial "está supeditado al respeto del principio de prohibición de la discriminación retributiva entre trabajadores masculinos y femeninos. Por tanto, este interés no puede constituir, por sí mismo, el único fundamento que justifique tal discriminación" ${ }^{69}$.

Así, puede existir diferencia salarial, aparentemente justificada por una distribución del trabajo en categorías profesionales dentro de la empresa (generalmente, en función del convenio colectivo de aplicación). Esta diferencia salarial no implica, necesariamente, la existencia de discriminación por razón de sexo; siempre y cuando esté justificada por el contenido del trabajo realizado.

Lo que puede suceder en estos supuestos es que la discriminación surja de la asignación de las personas trabajadoras a las diferentes categorías basada en factores que pueden tener que ver, directa o indirectamente, con el sexo. Esto hace surgir lo que llamamos puestos de trabajo feminizados o masculinizados, y tal como señala el Tribunal Constitucional, es la expresión más sutil y común de la discriminación por razón de sexo. "la que tiene lugar bajo apariencia de tratamientos formalmente no discriminatorios pero que encubren consecuencias para un grupo social determinado, generalmente femenino". Esta segregación puede diferenciarse entre horizontal, entendiéndose por tal aquella que se da por la existencia de "sectores económicos fuertemente feminizados (caso como el ámbito de la enseñanza, la sanidad o los servicios) y otros masculinizados (construcción e industria, por ejemplo)" y vertical, referida a aquella que se da respecto a "los empleos (categorías) que ocupan los hombres y las mujeres" y que es la que puede verse afectada, de manera directa, por la categorización dentro del convenio colectivo ${ }^{70}$.

A este respecto, el Tribunal Supremo ha señalado que, al menos en apariencia, puede existir discriminación salarial por razón de sexo cuando se establecen diferentes salarios para dos grupos profesionales estando el que percibiría un salario mayor formado mayoritariamente por hombres frente al otro grupo profesional, formado mayoritariamente por mujeres ${ }^{71}$. Sin embargo, y tal como recoge la sentencia, este detalle por sí solo no im-

\footnotetext{
${ }^{67}$ STC núm. 147/1995, de 16 de octubre (rec. 652/1993), FJ Tercero.

${ }^{68}$ En este sentido, cabe destacar el contenido del voto particular de la STC 250/2000 de 30 de octubre (rec. 2075/1996), donde señala el Magistrado que "la valoración de distintos trabajos, a efectos de su posible comparación, y más cuando la misma se establece en una negociación colectiva, no es un dato de carácter normativo", sino de carácter fáctico, por lo que debe cuestionarse si la valoración señalada respeta el principio de no discriminación establecido en el art. 14 CE o incurre en discriminación, aunque sea de forma indirecta.

${ }^{69}$ Apartado 48.

${ }^{70}$ CASAS BAAMONDE, M.E.; MENÉNDEZ CALVO, R.; et. al.: Herramientas para combatir..., op. cit., p.13.

${ }^{71}$ STS (Sala de lo Social) de 3 de noviembre de 2008 (rec. 169/2007), FD Segundo.
} 
plica la existencia de discriminación, sino que debe ser tenido en cuenta como un indicio. Se insiste así en la necesidad de analizar, siempre, el valor del trabajo para determinar si estos son o no de igual valor. En este sentido, el Tribunal Superior de Justicia de Islas Canarias señala que es irrelevante la categorización profesional, sino que lo que debe tenerse en cuenta, en todo caso, es las tareas realizadas en el puesto. Señala así que puede darse una segregación por puestos de trabajo que, en el fondo, realicen las mismas funciones ${ }^{72}$.

En este sentido, la STJCE ha señalado que el hecho de que la retribución fijada en negociación colectiva se lleve a cabo por los grupos profesionales afectados de manera separada y sin producir, dentro de cada grupo, un efecto discriminatorio, "no impide que se declare que existe una discriminación" cuando del resultado final se desprenda una diferencia salarial entre dos grupos profesionales de una misma empresa, pues el análisis debe basarse en si las funciones, tareas y exigencias del puesto son similares, así como en otros factores que resulten objetivos, no solo en que esta retribución sea el resultado de la negociación colectiva $^{73}$. Existe una práctica convencional de segregar a ambos sexos en dos categorías profesionales diferenciadas que genera una doble escala salarial y que, tal como ha señalado el Tribunal Constitucional, supone una discriminación salarial indirecta evidente ${ }^{74}$.

Ejemplo de ello es la STC núm. 145/1991, de 1 de julio (rec. 175/1989), donde la Sala entiende la existencia de discriminación salarial indirecta cuando se remunera de manera distinta a las trabajadoras incluidas en el grupo profesional de "limpiadoras" frente al de "peones", siendo el primero un grupo feminizado frente al segundo, masculinizado y teniendo en cuenta, además, que, si bien había funciones distintas, muchas eran comunes a ambos trabajos, por lo que estos tenían el mismo valor y debían ser retribuidos de igual modo $^{75}$. Parece que el debate sobre esta cuestión ya está superado, pero en la práctica, sigue encontrándose una categorización profesional que tiene en cuenta factores poco neutros, generando así una vez más, la disgregación y la doble escala salarial en función del sexo.

Por tanto, cuando la diferencia salarial parece estar justificada en una asignación diversa de categorías, "no basta con constatar la desigualdad de las tareas realizadas", sino que es necesario valorar que los criterios utilizados para asignar las categorías a los trabajadores y trabajadoras no son discriminatorios ${ }^{76}$.

Tal como ha señalado el Tribunal Constitucional, "para que un sistema de clasificación no sea discriminatorio en su conjunto, debe tomar en consideración, en la medida en que la naturaleza de las tareas a cumplir en la empresa lo permitan, criterios para los cuales los trabajadores de cada sexo sean susceptibles de presentar aptitudes particulares"77.

${ }^{72}$ Véase STSJ Islas Canarias (Las Palmas) (Sala de lo Social, Sección 1aㅡ), núm 2224/2014, de 19 de diciembre (rec. 428/2014), FD Único.

${ }^{73}$ STJCE de 27 de octubre de 1993 (Caso P.M. Enderby contra Frenchay Health Authority y otros), pág. 3.

${ }^{74}$ En este sentido, véase STC núm. 145/1992, de 13 de octubre (rec. 1071/1989)

${ }^{75}$ STC núm. 145/1991, de 1 de julio (rec. 175/1989), FJ Quinto. La Sala señala, además, que el convenio colectivo aplicable las separaba y definía como categorías diferenciadas, sin ser esto del todo relevante, pues la descripción de ambas categorías era genérica y podía ser equivalente, lo que lleva a determinar que se trata de una segregación por sexo que conlleva, además una discriminación salarial por esta causa.

${ }^{76}$ STC núm. 147/1995, de 16 de octubre (rec. 652/1993), FJ Segundo.

${ }^{77}$ STC núm. 250/2000, de 30 de octubre (rec. 2075/1996), Antecedente Octavo. 
En todo caso, para evitar la discriminación salarial indirecta por razón de sexo derivada de la feminización de ciertos puestos de trabajo de la empresa, debe aplicarse un sistema de valoración de puestos que resulte neutro, pues es la única forma de garantizar un sistema retributivo adecuado y no discriminatorio. Tanto es así que el propio Tribunal Constitucional ha señalado que, para determinar si existe discriminación salarial en una empresa entre un puesto ocupado mayoritariamente por mujeres frente a otro, ocupado en su mayoría por hombres, "no basta con comprobar la corrección formal de las diferencias salariales entre departamentos contenida en el convenio colectivo. Ha de tomarse en consideración, además, el trabajo efectivamente prestado y la concurrencia en él de circunstancias objetivamente acreditadas que no se vinculen directa o indirectamente al sexo de la persona"78. En definitiva, lo que debe comprobarse es si "la evaluación de las tareas llevada a cabo se ha producido con una repercusión salarial negativa en un determinado sexo" que verían así infravalorado su trabajo ${ }^{79}$.

En ocasiones, este problema no deriva de la categorización profesional sino del establecimiento de ciertos pluses en el convenio colectivo que pueden resultar discriminatorios ${ }^{80}$. Así, los tribunales señalan que para que un plus vinculado a la productividad no sea discriminatorio deberán "fijarse las cuantías del mismo con arreglo a condiciones objetivas", que no afecten de manera negativa a un grupo formado mayoritariamente por mujeres. Es decir, la cuantía debe ser la misma y los criterios para establecerla resultar neutros en cuanto al género. Algunos de estos criterios podrían ser "la existencia del trabajo a turnos o en horario nocturno, así como exigencias formativas como idiomas o cursos"; exigencias que deben estar vinculadas a la tarea realizada en cada puesto de trabajo y debidamente justificadas por su necesidad ${ }^{81}$.

Con relación a la cuestión aquí planteada, debe señalarse que el Tribunal Constitucional exige una mayor justificación en aquellos supuestos en que la discriminación salarial parece darse vinculada a los contratos de trabajo a tiempo parcial, ya sea por la categorización profesional o por quedar este tipo de personas trabajadoras fuera del campo de aplicación de algunos pluses previstos por el convenio colectivo. Esto es así porque, tal como señala la STC (Sala Primera) núm. 22/1994, de 27 de enero (rec. 2550/1991), en su FJ Cuarto, en los contratos a tiempo parcial existe un alto porcentaje de mano de obra femenina ${ }^{82}$, lo que hace que pueda existir discriminación indirecta y "exigiéndose, por tanto, una más cuidadosa justificación de las desigualdades salariales”, atendiendo a factores que vayan más allá del tiempo de trabajo ${ }^{83}$.

\footnotetext{
${ }^{78}$ STC (Sala Primera) núm. 286/1994, de 27 de octubre (rec. 175/1994), FJ Tercero.

${ }^{79}$ STC núm. 147/1995, de 16 de octubre (rec. 652/1993), FJ Tercero.

${ }^{80}$ En este sentido, véase CASAS BAAMONDE, M.E.; MENÉNDEZ CALVO, R.; et. al.: Herramientas para combatir..., op. cit., 2015.

${ }^{81}$ En este sentido, véase STSJ Islas Canarias (Santa Cruz de Tenerife) (Sala de lo Social), núm. 928/2017 de 2 de noviembre (rec. 461/2017), FD Segundo.

${ }^{82}$ En este sentido, véase también CASAS BAAMONDE, M.E.; MENÉNDEZ CALVO, R.; et. al.: Herramientas para combatir..., op. cit., p. 13.

${ }^{83}$ En este sentido, véase también MIRANDA BOTO, J.M.: "Trabajo a tiempo parcial, horas extraordinarias y discriminación por razón de sexo", Revista Doctrinal Aranzadi Social, núm. 21/2007, p. 1324.
} 


\section{El poder de organización y dirección empresarial y los límites en torno a la discriminación salarial}

Como se sabe, el empresario tiene la facultad de dirigir y organizar su empresa para obtener los objetivos que este persigue. Si bien es cierto que este poder de dirección y organización empresarial no es absoluto e ilimitado, puede permitirle alterar, de manera unilateral, condiciones laborales no esenciales.

A este respecto, existen numerosas sentencias que abordan la cuestión de si un determinado plus, ya sea convencional o pagado de manera voluntaria por el empresario, puede constituir discriminación salarial por razón de sexo. El Tribunal Supremo ha entendido que, para apreciarse la discriminación salarial indirecta en estos casos, la empresa no debe poder justificar, de manera objetiva y razonable la disparidad salarial derivada del pago de un plus concreto a ciertos trabajadores ${ }^{84}$.

En primer lugar, respecto a la libertad empresarial de establecer diferencias salariales en su empresa, la Sala entiende que, si bien es cierto que el empresario podría establecer diferencias salariales dentro de su libertad y autonomía en la gestión de su empresa, no puede hacerlo si esto supone una distinción de trato basada, exclusivamente, en el sexo del trabajador. Esto supone que un plus voluntario no convencional, cuando no esté vinculado al desarrollo del propio trabajo, "evidencia que, de forma aparentemente neutra y objetiva, la empresa signa el plus al margen de cualquier capacitación profesional de quienes lo perciben" y que, si bien es cierto que el empresario "no está obligado a otorgar un trato igual a todos sus trabajadores, pudiendo establecer aquellas diferencias que le parezcan más convenientes en orden a sus propios interese empresariales", lo que no puede hacer es "asignar unas cantidades significativamente inferiores" de dicho plus a departamentos o puestos de trabajo mayoritariamente ocupados por mujeres frente a los ocupados por hombres ${ }^{85}$. Es decir, también en las acciones que lleve a cabo en materia retributiva dentro de su libertad como empresario, deberá respetar el principio de igualdad salarial entre hombres y mujeres.

Al hilo de lo anterior, los pluses que los estudios señalan como origen de discriminación salarial indirecta entre hombres y mujeres son varios y están relacionados, principalmente, con las tareas y características propias del puesto de trabajo y de las funciones desarrolladas.

Dentro de este grupo se incluye, por ejemplo, el plus de nocturnidad. Este plus no presenta grandes problemas con relación a la discriminación, pues retribuye el trabajo dentro de una horquilla horaria preestablecida por la normativa en el art. 36 TRET. Sin embargo, puede generar discriminación salarial indirecta cuando se calcula aplicando un porcentaje sobre el salario base, pues como ya se ha señalado, que las mujeres cobran menos que los hombres es un hecho.

En cuanto a los pluses de penosidad, peligrosidad o toxicidad, la discriminación surge por la existencia de puestos de trabajo feminizados y masculinizados, ya que ge-

\footnotetext{
${ }^{84}$ En este sentido, véase STS (Sala de lo Social) de 14 de mayo de 2014 (rec. 2328/2013).

${ }^{85}$ STS (Sala de lo Social) de 14 de mayo de 2014 (rec. 2328/2013). FD Segundo.
} 
neralmente están vinculado a categorías profesionales o funciones especialmente masculinizadas $^{86}$. En este caso, se deben tener en cuenta para su abono factores que pueden generar discriminación indirecta por razón de género, pues son propios de esos trabajos masculinizados. Sin embargo, no se valoran factores que podrían ser similares para trabajos feminizados. Ejemplo de ello sería valorar la carga física a la hora de determinar qué categorías se benefician del plus de penosidad y no valorar, para el abono de dicho plus, la carga mental de un trabajo. En todo caso, su cuantía está también vinculada, en ocasiones, al salario base, aplicando sobre este un porcentaje; lo cual, y como se ha señalado, puede también generar discriminación salarial indirecta.

Respecto al plus de desempeño, la situación es similar. En primer lugar, para garantizar la neutralidad del mismo es indispensable partir de una valoración de puestos de trabajo y del desempeño del mismo por el empleado que resulte no solo objetiva, sino neutra en cuanto al género. Además, tal como pone de manifiesto el estudio realizado por la Universidad Complutense de Madrid, hay un peligro concreto, pues existen convenios que no lo concretan, dejando esta cuestión al "acuerdo entre los representantes y el empresario", lo que podría generar "su pago aleatoriamente, por decisión unilateral de la empresa" y sin tener en cuenta criterios de neutralidad que garanticen el respeto al principio de igualdad retributiva ${ }^{87}$.

Pese a existir muchos otros pluses, como el de flexibilidad, festivos, sábados o domingos o vinculados a la productividad, debe señalarse que los mencionados son los que mayores diferencias salariales vinculadas al género pueden causar en la práctica ${ }^{88}$.

Tal como señalan CASAS BAAMONDE, et. al., la regulación ideal de este tipo de complementos "para impedir posibles brechas salariales es que se cuantifique igual para todos", sin distinciones en función de la categoría profesional y sin vincularlo, en ningún caso, al salario base. Es decir, estableciendo un importe que se aplique de igual manera a todo el personal de la empresa. Además, para pluses en los que se está valorando en mayor medida características propiamente masculinas, deberán tenerse en cuenta para su asignación otras cualidades vinculadas a funciones feminizadas e incluso otras que puedan ser aplicadas de manera indistinta, sin cuestiones de género que acaben con la neutralidad pretendida.

En este sentido, la STSJ Islas Canarias (Las Palmas) (Sala de lo Social, Sección 1aa), núm. 2224/2014 de 19 de diciembre (rec. 428/2014) señala que "la prohibición de discriminación excluye el recurso a criterios de evaluación sexualmente caracterizados, imponiéndose el uso de criterios neutros, basados en atributos igualmente predicables de ambos géneros" ${ }^{89}$.

Con relación a los intereses de la empresa, existe un factor que debe ser tenido en cuenta: la falta de candidatos para ocupar un puesto de trabajo determinado en el mercado de trabajo. En estas circunstancias, puede darse el caso de que la empresa se vea obligada a ofrecer una retribución superior para un concreto puesto de trabajo, con el fin de

\footnotetext{
${ }^{86}$ En este sentido, véase CASAS BAAMONDE, M.E.; MENÉNDEZ CALVO, R.; et. al.: Herramientas para combatir..., op. cit., p. 62.

${ }^{87}$ Ibidem..., pp. 47 y ss.

${ }^{88}$ Para saber más sobre la redacción de estos pluses y su vinculación a la brecha salarial, ibidem..., p. 62

${ }^{89}$ FD Único.
} 
atraer a los posibles candidatos. Esto podría justificar, de manera objetiva, una diferencia en la retribución ${ }^{90}$.

Sin embargo, en este caso se corre el riesgo de que la diferencia de trato venga dada porque este tipo de ofertas sean propias de puestos de trabajo o sectores de actividad masculinizados, por lo que también deberá estar justificada con base en factores objetivos y que resulten neutros.

\section{Sistemas de valoración de puestos de trabajo: tipos y características principales}

Antes de analizar los diferentes sistemas de valoración de puestos de trabajo debe señalarse que todos ellos tienen un objetivo común: "intentar eliminar las influencias personales e introducir procedimientos definidos que permitan obtener una valoración objetiva de los puestos de trabajo" 91 .

Por otra parte, debe tenerse en cuenta que existen numerosos sistemas de valoración de puestos de trabajo, y que cada empresa adapta los ya existentes, o incluso crea su propio sistema interno ${ }^{92}$. Lo que se pretende en el presente apartado es realizar un marco genérico en el que se detallen los principales tipos de sistemas y sus características, sin entrar a analizar en detalle cada uno de ellos, pues lo que interesa es la posibilidad de que en cualquier sistema de análisis sea posible incurrir en discriminación indirecta. Para ello, se hablará de los sistemas de valoración de puestos de trabajo diferenciando dos grandes grupos: los sistemas cualitativos y los cuantitativos.

\section{Sistemas de valoración de puestos cualitativos}

Al hablar se métodos cualitativos de valoración de puestos de trabajo se hace referencia a aquellos que "proporcionan una ordenación de los puestos de trabajo de la organización, desde el más importante hasta el menos, pero no aportan un valor numérico en la ordenación y, como consecuencia, no se conocen las diferencias en valor existentes entre los puestos" ${ }^{\prime 3}$. Este tipo de sistema "determina el peso relativo de los puestos comparándolos con descripciones generales" ${ }^{\prime 4}$, pero sin analizar en detalle las funciones y tareas desem-

\footnotetext{
${ }^{90}$ En este sentido, véase STJCE de 27 de octubre de 1993 (Caso P.M. Enderby contra Frenchay Health Authority y otros), pág. 3.

${ }^{91}$ CEPEDA CARRIÓN, G.: “La valoración de puestos en la práctica: un análisis de convenios colectivos”, en La gestión de la diversidad: XIII Congreso Nacional, IX Congreso Hispano-Francés, Logroño, 1999, p. 179.

${ }_{92}$ Tal como señalan PEREDA MARÍN y BERROCAL BERROCAL, "las técnicas utilizadas por las diversas organizaciones para valorar sus puestos de trabajo han sido múltiples, y todas ellas tratan de ordenarlos en función de su valor o utilidad relativos para las mismas". En PEREDA MARÍN, S. y BERROCAL BERROCAL, F.: Valoración de puestos de trabajo..., op. cit., p. 19. En similar sentido, véase POELS, F.: Estrategias de valoración y remuneración de puestos de trabajo, FC Editorial, Madrid, 2001, p. 107, donde señala que "En Europa se están utilizando en la actualidad, más de 100 métodos de valoración distintos".

${ }^{3}$ PEREDA MARÍN, S. y BERROCAL BERROCAL, F.: Valoración de puestos de trabajo..., op. cit., p. 19. Entre estos métodos están, tal como señalan los autores, el Método de Graduación, el Método de Clasificación o el Método del Mercado de Salarios.

${ }^{94}$ POELS, F.: Estrategias de valoración y remuneración..., op. cit., p. 107.
} 
peñadas en cada uno de ellos. Por ello, también son llamados "métodos globales" o "no analíticos".

En estos casos, se utilizan uno o varios criterios generales para determinar la importancia de cada puesto de trabajo dentro de la organización. Es decir, su objetivo es "la ordenación jerárquica de los puestos de trabajo" sin entrar a valorar su contenido y diferencias entre ellos ${ }^{95}$. Su fortaleza reside en la simplicidad de su aplicación ${ }^{96}$.

Estos criterios son, en todo caso, valorados por otras personas, lo que hace que sean subjetivos pues dependen, en ocasiones, de la percepción de estas. Con el objetivo de eliminar dicha subjetividad en la valoración, algunos expertos proponen la evaluación por pares ${ }^{97}$. El más utilizado de estos métodos es el Método de Clasificación, consistente en "agrupar los distintos puestos, considerando globalmente cada uno de ellos, en una serie de grados, previamente definidos y clasificados en una hipotética escala de importancia" 98 .

En todo caso, y debido a la subjetividad que subyace en su diseño, estos sistemas no son los más adecuados, y, en todo caso, "no ofrecen pruebas documentales que permitan defender la compensación final obtenida por un puesto" ${ }^{99} \mathrm{y}$, por tanto, no puede asegurarse, en ningún caso, su neutralidad y su utilidad específica en la lucha contra la discriminación salarial indirecta por razón de género.

Podría decirse, por lo tanto, que este tipo de sistemas no serían los más adecuados, ya que, además de partir de una valoración más o menos subjetiva, no tienen en cuenta los factores señalados por el art. 28 TRET para determinar si dos o más trabajos pueden considerarse "iguales" o de "igual valor" y, aun en los casos en que sean valorados algunos de estos factores, no son objetivados ni se utilizan criterios neutros para su valoración.

\section{Sistemas de valoración de puestos cuantitativos}

Si bien es cierto que los sistemas de valoración de puestos de trabajo cualitativos pueden suponer un problema, ya que podría generar discriminación salarial indirecta al tener un marcado carácter subjetivo, no ocurre lo mismo con los sistemas de valoración de puestos de trabajo cuantitativos

Los métodos cuantitativos -también llamados analíticos- son aquellos que, tras un análisis detallado del contenido de cada puesto de trabajo, otorgan a este un valor numérico. Por tanto, permite "conocer no sólo su ordenación, sino las diferencias existentes entre

\footnotetext{
${ }^{95}$ BERROCAL BERROCAL, F.: Análisis comparativo de tres métodos de valoración de puestos de trabajo, Universidad Complutense de Madrid, 2016, p. 103.

${ }^{96}$ Ibidem..., p. 104.

${ }^{97}$ Es el caso del Método de Graduación. Para obtener más información sobre el mismo, véase PEREDA MARÍN, S. y BERROCAL BERROCAL, F.: Valoración de puestos de trabajo..., op. cit., pp. 23 y ss. Igualmente, lo recomienda la Comisión Nacional de Productividad Industrial en su documento Valoración de puestos de trabajo, salarios e incentivos, Madrid, 1963 y FERNÁNDEZ-RÍOS, M. y SÁNCHEZ, J.C.: Valoración de puestos de trabajo: fundamentos, métodos y ejercicios, Díaz de Santos, Madrid, 1997.

${ }^{98}$ PEREDA MARÍN, S. y BERROCAL BERROCAL, F.: Valoración de puestos de trabajo..., op. cit., p. 33.

${ }^{99}$ BERROCAL BERROCAL, F.: Análisis comparativo..., op. cit., p. 105.
} 
el valor de los mismos" ${ }^{100}$. Dentro de este grupo se puede diferenciar entre el método de puntuación y el de comparación de factores.

Estos métodos se basan en la utilización de una serie de factores para determinar el valor y la similitud entre los diferentes puestos de trabajo de la empresa. A este respecto, se entiende por factor aquellas "características o componentes del trabajo comunes a diferentes puestos de trabajo y que tienen una importancia distinta en cada uno de ellos"101. Es decir, se analizan una serie de cualidades, características o exigencias de un puesto de trabajo que, en conjunto, forman dicho puesto.

Con el fin de mantener la objetividad del sistema, los factores seleccionados para su valoración deben ser comunes a los diferentes puestos de trabajo de la empresa, y tener un peso diferente en cada trabajo, con objeto de otorgar en cada caso la importancia que tiene. Estos factores pueden dividirse en cuatro grandes grupos: aptitudes, esfuerzo, responsabilidad y condiciones de trabajo ${ }^{102}$.

En todo caso, los factores a valorar deben estar relacionados con el puesto de trabajo y las funciones realizadas, nunca con las características personales del trabajador que lo ocupe ${ }^{103}$. Además, deberán cumplir con una serie de requisitos, como ser comunes a todos los puestos analizados o, al menos, a gran parte de ellos; permitir la variabilidad en su análisis por tener más peso en unos puestos que en otros; identificar las diferencias más relevantes entre los distintos puestos de trabajo y la posibilidad de ser graduados en diferentes niveles según su importancia en el puesto ${ }^{104}$.

Como puede verse, este tipo de sistema de valoración de puestos de trabajo encaja en la definición que el art. 28 TRET realiza para determinar si un trabajo es de "igual valor" pues, como señala el citado artículo, deben tenerse en cuenta "la naturaleza de las funciones o tareas efectivamente encomendadas, las condiciones educativas, profesionales $o$ de formación exigidas para su ejercicio, los factores estrictamente relacionados con su desempeño y las condiciones laborales en las que dichas actividades se llevan a cabo en realidad sean equivalentes", y estos son diferentes factores que se analizan y valoran, tal como se detalla a continuación, en los sistemas de valoración de puestos de trabajo cuantitativos. Por ello, y tal como señalan PEREDA MARÍN y BERROCAL BERROCAL, este tipo de sistema "favorece el establecimiento posterior de los salarios" 105.

${ }^{100}$ PEREDA MARÍN, S. y BERROCAL BERROCAL, F.: Valoración de puestos de trabajo..., op. cit., p. 19. Destacan, entre los métodos cuantitativos, el Método de Comparación de Factores (recomendado por diversos organismos nacionales e internacionales), el Método de Puntuación, el Método de los Componentes de Trabajo o el Sistema HAY.

${ }^{101}$ PEREDA MARÍN, S. y BERROCAL BERROCAL, F.: Valoración de puestos de trabajo..., op. cit., p. 37. Para saber más sobre este tipo de sistemas de evaluación de puestos de trabajo, véase FERNÁNDEZ-RÍOS, M.: Análisis y descripción de puestos..., op. cit., pp. 223 y ss.

${ }^{102}$ PEREDA MARÍN, S. y BERROCAL BERROCAL, F.: Valoración de puestos de trabajo, op. cit., pp. 38 y 39.

${ }^{103}$ A este respecto, BERROCAL BERROCAL señala que, aunque estos factores "pueden ser apropiados en muchos entornos y a su vez pueden ser el paraguas de subfactores más específicos, no deben adoptarse de forma automática, al deber poderse adaptar a los objetivos, la cultura y los valores de la organización, por lo que podría ser necesario incluir nuevos factores como, por ejemplo, las exigencias emocionales" u otros que reflejen las competencias exigidas por la tarea y puesto de trabajo. En BERROCAL BERROCAL, F.: Análisis comparativo..., op. cit., p. 116.

${ }^{104}$ Ibidem..., pp. 108 y 109.

${ }^{105}$ PEREDA MARÍN, S. y BERROCAL BERROCAL, F.: Valoración de puestos de trabajo..., op. cit., p. 37. 


\subsection{Aptitudes}

Las aptitudes hacen referencia a la capacidad de las personas para desempeñar de forma adecuada una actividad específica o un conjunto de tareas que conforman el puesto de trabajo. Entre las aptitudes que deben tenerse en cuenta en la valoración de puestos de trabajo están las exigencias mentales de las tareas realizadas, la formación académica, la iniciativa, la experiencia profesional, el tiempo requerido de adaptación al puesto, las habilidades sociales necesarias, la dificultad del trabajo, la aptitud para tomar decisiones, la versatilidad o la creatividad ${ }^{106}$.

\subsection{Esfuerzo}

Habitualmente se entiende por esfuerzo en el ámbito laboral a aquellas actividades físicas que son necesarias para desempeñar las funciones intrínsecas al puesto de trabajo, como pueden ser levantar y soportar cargas, realizar movimientos repetitivos, mantener una postura durante un tiempo determinado, etc. Sin embargo, a la hora de establecer un sistema de valoración de puestos de trabajo neutro con relación al género, debemos tener en cuenta que el factor "esfuerzo" debe incluir, no solo el esfuerzo y la exigencia física del puesto de trabajo o la fatiga física, sino también la fatiga y el esfuerzo mentales derivado del mismo. Igualmente, deberá tenerse en cuenta la carga de trabajo (tanto cuantitativa como cualitativa), la necesidad de concentración, la monotonía, el esfuerzo visual o el esfuerzo muscular entre otras ${ }^{107}$.

\subsection{Responsabilidad}

Al hablar de responsabilidad en el puesto de trabajo debe ser referida, no solo al nivel de compromiso que el trabajador asuma respecto a la empresa, sino a la responsabilidad que el trabajador tiene dentro de las funciones que desarrolla en su puesto de trabajo. Además, deberá tenerse en cuenta si el trabajador es responsable de la seguridad de terceras personas, de los materiales, equipos y productos utilizados, o incluso de la economía de la empresa. También debe analizarse el coste de sus errores tanto para la empresa como para el propio trabajador, si precisa supervisión (y en caso afirmativo, si constante o esporádica), o la responsabilidad que éste tiene sobre la calidad del servicio prestado. Otro aspecto a tener en cuenta a la hora de valorar el nivel de responsabilidad que exige un puesto de trabajo es el manejo de datos confidenciales de la empresa o de terceras personas, así como el hecho de que el puesto suponga ser responsable de la gestión de las relaciones personales de un grupo de trabajadores y trabajadoras de la empresa ${ }^{108}$.

\footnotetext{
${ }^{106}$ Ibidem..., pp. 38 y 39.

${ }^{107}$ En este sentido, ibidem..., pp. 38 y 39.

${ }^{108}$ Ibidem..., pp. 38 y 39.
} 


\subsection{Condiciones de trabajo}

Por último, se deben analizar las condiciones de trabajo relativas al puesto a valorar. Al hablar de condiciones de trabajo se hace referencia al ruido, humedad, temperatura, riesgos personales en el puesto de trabajo, monotonía, viajes, ambiente de trabajo en general, vibraciones, horario, permisos o la posibilidad de contraer enfermedades profesionales. Es decir, se considerará incluido en este grupo de análisis a cualquier aspecto del trabajo que pueda tener consecuencias negativas para la salud de las personas trabajadoras, incluyendo tanto los aspectos ambientales como los tecnológicos y las cuestiones relativas a la organización y la ordenación del trabajo. También serán tenidos en cuenta si pueden tener consecuencias positivas, pues su nivel de influencia en el trabajo deberá ser tenido en cuenta en el proceso de valoración ${ }^{109}$.

\section{Conclusiones}

Es indudable que, en las últimas décadas, se ha avanzado en la igualdad entre hombres y mujeres a través de la promulgación de diversa normativa, tanto a nivel europeo como en el ámbito nacional. Sin embargo, todavía se está lejos de conseguir una igualdad real, completa y efectiva entre hombres y mujeres en materia salarial, tal como muestran los datos más recientes de Eurostat o del Instituto de la Mujer, entre otros organismos.

Con relación al principio de igualdad retributiva entre hombres y mujeres debe señalarse que, en numerosas ocasiones, se da de manera indirecta. A ello contribuyen cuestiones de importante calado social, como la tradicional disgregación sexual en los puestos de trabajo y categorías profesionales previstas en los convenios colectivos o la valoración superior que se otorga a aquellos trabajos cuyo contenido reviste de características propiamente masculinas, olvidando cuestiones como la carga mental en el trabajo. Ante esta problemática, tanto el Tribunal de Justicia de la Unión Europea como los Tribunales españoles y, de manera especial, el Tribunal Constitucional, han sido claros. Cuando la diferencia salarial esté justificada en la propia asignación salarial a las categorías convencionales no será suficiente con que las tareas realizadas se muestren como diferentes, sino que será preciso valorar los criterios utilizados para asignar las categorías al personal, con objeto de determinar si estos resultan discriminatorios. Además, y en todo caso, será necesario ir más allá, y demostrar que en las diferentes categorías no se realizan trabajos que puedan ser considerados como similares o de igual valor. De ello se concluye que la corrección formal de las diferencias salariales derivada de la clasificación profesional en el convenio colectivo no basta para justificar la inexistencia de discriminación, siendo lo relevante, en todo momento, el contenido esencial y el valor del trabajo realizado.

Con relación a lo anterior, es determinante la importancia de aplicar, de manera correcta, el contenido del art. 28 TRET, especialmente en lo referido a la valoración de cier-

\footnotetext{
${ }^{109}$ Ibidem..., pp. 38 y 39
} 
tos factores, como la formación, las condiciones laborales, la experiencia requerida o la responsabilidad vinculada al puesto de trabajo. En todo caso, los criterios de valoración siempre deberán ser neutros, entendiendo por tales aquellos en que los trabajadores de cada sexo puedan presentar aptitudes, sin beneficiar a uno u otro sexo por ser cualidades feminizadas o masculinizadas.

Por todo ello, los sistemas de valoración de puestos de trabajo cuantitativos se muestran como una herramienta de gran utilidad para luchar contra la desigualdad salarial, por una parte, asegurando al mismo tiempo el cumplimiento del contenido del art. 28 TRET con relación a lo que debe ser considerado como trabajo de igual valor dentro de la empresa.

\section{Bibliografía}

Comunicación de la Comisión al Parlamento Europeo, al Consejo y al Comité Económico y Social Europeo.

Código práctico sobre la aplicación de la igualdad de retribuciones entre mujeres y hombres para un trabajo de igual valor, EMAKUNDE, Bilbao, 1997.

Guía y recomendaciones de uso de la herramienta sistema de valoración de puestos de trabajo en las empresas con perspectiva de género, Instituto de la Mujer.

Plan de Acción de la UE 2017-2019. Abordar la brecha salarial entre hombres y mujeres, 2017.

Promoción de la igualdad salarial por medio de la evaluación no sexista de los empleos: Guía detallada, OIT, Ginebra, 2008.

Valoración de puestos de trabajo con perspectiva de género, Instituto de la Mujer, Madrid, 2015.

Recomendación General número 13 de la CEDAW sobre igualdad de remuneración por trabajo de igual valor.

Valoración de puestos de trabajo, salarios e incentivos, Comisión Nacional de Productividad Industrial, Madrid, 1963.

BALLESTER PASTOR, M.A.: "Normativa nacional en materia de igualdad de trato en el ámbito laboral de la Seguridad Social", en Revista Doctrinal Aranzadi, 1998.

BALLESTER PASTOR, M.A.: Diferencia y discriminación normativa por razón de sexo en el orden laboral, Tirant Lo Blanch, Valencia, 1994.

BALLESTER PASTOR, M.A.: "La discriminación retributiva por razón de sexo en la Unión Europea”, en Documentación Laboral, no 115, 2018, Vol. III, Cinca, Madrid, 2018, pp. 13-31.

BERROCAL BERROCAL, F.: Análisis comparativo de tres métodos de valoración de puestos de trabajo, Universidad Complutense de Madrid, 2016.

BOLL, C. y LAGERMAN, A.: Gender pay gap in EU countries based on SES, Comisión Europea, Fondazione Giacomo Brodolini, Roma, 2018.BALLESTER PASTOR, M.A.: "La discriminación retributiva por razón de sexo en la Unión Europea”, en Documentación Laboral, no 115, 2018, Vol. III, Cinca, Madrid, 2018. 
BOLL, C.; LEPPIN, J.; ROSSEN, A. y WOLF, A.: Magnitude and impact factors of the gender pay gap in EU Countries, Dirección General de Justicia y Consumidores de la Comisión Europea, 2016.

CASAS BAAMONDE, M.E.; MENÉNDEZ CALVO, R.; QUINTANILLA NAVARRO, B. y SERRANO GARCÍA, J.M.: Herramientas para combatir la brecha salarial. Análisis de los factores que influyen en la brecha salarial, Comisión Ejecutiva Confederal UGT, Madrid, 2015.

CEPEDA CARRIÓN, G.: "La valoración de puestos en la práctica: un análisis de convenios colectivos", en La gestión de la diversidad: XIII Congreso Nacional, IX Congreso Hispano-Francés, Logroño, 1999

COROMINAS, A.; COVES, A.M.; LUSA, A.; MARTÍNEZ, M.C. y ORTEGA, M.A.: “El papel de la valoración de puestos de trabajo en la discriminación salarial de la mujer", Encuentro Mujer y Trabajo. Un debate sobre la igualdad, Santander, 1999.

COVES, A.M.; LUSA, A.; MARTÍNEZ, C. y ORTEGA, M.A.: "Aplicación de la valoración de puestos de trabajo como herramienta para combatir la discriminación salarial", en $I$ Workshop de ingeniería de Organización, Bilbao, 2000.

FERNÁNDEZ DOMÍNGUEZ, J.J.: La mujer ante el Derecho de la Seguridad Social. Antiguos y nuevos problemas de la igualdad de trato por razón de sexo, La Ley, Madrid, 1999.

FERNÁNDEZ RIOS, M.: Análisis y descripción de puestos de trabajo, Ediciones Díaz de Santos, Madrid, 1995.

FERNÁNDEZ-RÍOS, M. y SÁNCHEZ, J.C.: Valoración de puestos de trabajo: fundamentos, métodos y ejercicios, Díaz de Santos, Madrid, 1997.

GOI SEIN, J.L.: "La reduccin de la brecha salarial de gnero a travs de la transparencia y el registro salarial”, en RODRÍGUEZ SANZ DE GALDEANO, B. (Dir.); et. al.: La discriminacin de la mujer en el trabajo y las nuevas medidas legales para garantizar la igualdad de trato en el empleo, Aranzadi, Cizur Menor, 2020,

MIRANDA BOTO, J.M.: "Trabajo a tiempo parcial, horas extraordinarias y discriminación por razón de sexo", Revista Doctrinal Aranzadi Social, núm. 21/2007, pp. 1323-1325.

PEREDA MARÍN, S. y BERROCAL BERROCAL, F.: Valoración de puestos de trabajo, Eudema, Madrid, 1993.

POELS, F.: Estrategias de valoración y remuneración de puestos de trabajo, FC Editorial, Madrid, 2001.

TORRENTE GARI, S.: La mujer y la protección social, Ministerio de Trabajo y Asuntos Sociales; Madrid; 1999; p. 17. 